\title{
SOFT-TISSUE RELEASE OF THE KNEE IN CHILDREN WITH JUVENILE CHRONIC ARTHRITIS
}

\author{
D. W. ClARKE, BARBARA M. ANSELL, M. SWANN \\ From Wexham Park Hospital, Slough
}

\begin{abstract}
We report the results of 23 soft-tissue release procedures in 15 patients who had juvenile chronic arthritis. The operation, which includes hamstring tenotomies and posterior capsulotomy, is a safe and effective way of eliminating contracture, relieving pain and improving function.
\end{abstract}

Flexion contracture of the hip and of the knee represents a major cause of disability in patients with juvenile chronic arthritis; moreover, the knee is involved in $65 \%$ of cases within a year of onset of the disease (Arden and Ansell 1978), and about 33\% of patients will have persistent symptoms and signs at five years (Fiszman, Ansell and Renton 1981). Changes within the joint range from early synovial proliferation with effusion to fibrous ankylosis: these result not only from the destruction caused by pannus but also from the secondary effects produced by loss of weight-bearing, deformity, lack of congruity of joint surfaces, loss of movement and (possibly) a rise of pressure within the joint.

A soft-tissue release may be considered as long as some joint space can be demonstrated and valgus deformity does not exceed $15^{\circ}$. The operation, considerably more difficult than soft-tissue release at the hip (Swann and Ansell 1986) aims to release hamstring spasm, to correct flexion deformity, to increase the range of movement, to relieve pain and to improve the functional capabilities of the joint, all of which contribute to the patient's mobility. Although disease activity after operation may affect the final outcome, the immediate results of the procedure are worthwhile and, in most patients, maintained for a long period.

\section{PATIENTS AND METHODS}

There were 15 patients ( 10 boys and five girls) under the care of the Juvenile Rheumatism Unit at the Canadian Red Cross Memorial Hospital, Taplow, and subsequently at Wexham Park Hospital, Slough. All had been

D. W. Clarke, FRCS, Senior Orthopaedic Registrar

B. M. Ansell, CBE, MD, FRCS, FRCP, Consultant Rheumatologist

M. Swann, FRCS, Consultant Orthopaedic Surgeon

Wexham Park Hospital. Slough, Berkshire SL2 4HL, England.

Requests for reprints should be sent to Mr M. Swann.

(C) 1988 British Editorial Society of Bone and Joint Surgery $0301-620 \times / 88 / 2056 \$ 2.00$

J Bone Joint Surg [Br] 1988:70-B:224-7. receiving a full regimen of medication, splintage and physiotherapy.

Eight bilateral and seven unilateral procedures were performed on a total of 23 knees. The mean age of the patients at operation was 12 years 8 months; the mean interval between the onset of symptoms in the knee and operation was 8 years 6 months. Four had had a systemic onset, one a polyarticular and eight a pauci-articular onset. One patient had seropositive polyarthritis, and one juvenile ankylosing spondylitis. At the time of operation three patients had active disease involving the knee and 12 were quiescent. Seven previous operations had been performed on the operated knee, including three arthrotomies to release patellar adhesions, two synovial biopsies and two supracondylar osteotomies. Twenty-four prior procedures had been performed on the hips (14 soft-tissue releases and five bilateral total hip replacements).

Operation. Under tourniquet control, the joint is approached by posteromedial and posterolateral incisions. The hamstring tendons are divided or lengthened and the incision deepened beneath the heads of the gastrocnemius across the back of the posterior capsule. The capsular division must be carried around the sides of the joint so that it passes anterior to the axis of rotation of the knee, thus encroaching on the quadriceps expansion on each side. If the tibia is subluxed posteriorly on the femur, a tightly contracted anterior cruciate ligament may be discovered and must then be divided.

The wounds are closed with suction drainage and a split-plaster cylinder applied to the leg in the position of maximum unforced correction, ensuring that the neurovascular state of the foot is satisfactory.

Further straightening is carried out gradually in the postoperative period. After 48 hours the plaster is bivalved to allow active movement and sessions on a continuous passive-movement machine. The posterior half of the cast is used for walking and as a rest-splint, but removed for non-weight-bearing exercises. The stitches are removed on the twelfth day and hydrotherapy begun. 
It is essential that for at least one year splintage is worn when the knee is at rest.

\section{RESULTS}

All 15 patients were seen routinely at six months after surgery. At the time of review, only 13 patients ( 21 knees) were available for examination as one patient had died of amyloidosis and one had undergone a total knee replacement. The mean review period was 5 years 2 months, and no patient was followed up for less that one year. There were no neurovascular complications, and wound healing was uneventful.

Flexion contracture. This decreased from a mean of $34^{\circ}$ before operation (range $15^{\circ}$ to $80^{\circ}$ ) to $11^{\circ}$ (range $0^{\circ}$ to $20^{\circ}$ ) at six months after surgery. At review two knees were able to extend fully and 16 had less than $15^{\circ}$ of flexion contracture (Fig. 1). Two knees developed contractures greater than at the time of surgery: one deteriorated as the result of disease activity and the second failed to comply with the postoperative rehabilitation programme.

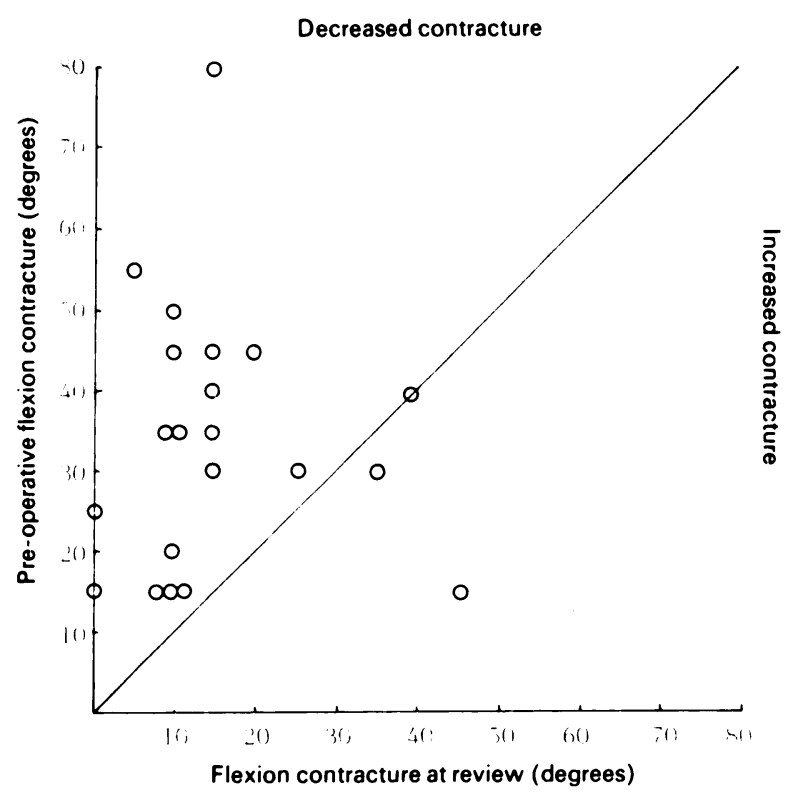

Fig. 1

At review $16 \mathrm{knees}$ had $15^{\circ}$ or less of flexion contracture (two knees had developed contractures greater than before operation).

Range of movement. The mean range of movement showed a slight increase from $53^{\circ}$ before operation (range $35^{\circ}$ to $140^{\circ}$ ) to $60^{\circ}$ at review (range $15^{\circ}$ to $145^{\circ}$ ).

Pain. This was scored from 0 (unbearable pain all the time) to 10 (no pain) (Salvati and Wilson 1973). The score increased from 4.77 before operation to 7.23 six months after operation, an improvement which had been maintained at the time of this review.

Mobility and function. The patients' walking.ability and functional capabilities were assessed by a scoring system adapted from the knee function chart of the British Orthopaedic Association Research Subcommittee (Aich- roth et al. 1978). Zero indicated that a patient was bedridden and completely dependent on others, and 10 indicated that the patient could walk without support, with no limp and could engage in normal activities. In both assessments an improvement was recorded: mobility was 3.36 before operation and 6.00 at review, while function was 2.15 before operation and 5.15 after.

Radiological change. The thick hyaline articular cartilage layer in children precludes radiological assessment of the joint until extensive destruction and consequent bone changes occur (Fiszman et al. 1981). Radiographs were thus not helpful in evaluating the effects of operation except to visualise the alignment and congruity of the joint and to assess improvement in bone density. A minor degree of residual tibial subluxation was noted on the postoperative radiographs of five knees.

\section{DISCUSSION}

The overall development of the knee can be seriously affected in juvenile chronic arthritis; indeed, the knee illustrates clearly the destructive mechanical factors involved as well as epiphyseal growth derangement. An early manifestation of inflammation within the joint is flexion deformity due to synovial swelling, effusion and pain, and secondary quadriceps wasting and hamstring spasm impede the patients' ability to correct the deformity. Finally, capsular fibrosis and contracture which may also affect the anterior cruciate ligament produces a fixed deformity with posterior subluxation of the tibia (Somerville 1960). Some patients exhibit abnormalities of epiphyseal growth around the knee: the tibial plateau may slope forwards and down, contributing to the subluxation, the patella grows misshapen, and, early in the disease, adhesions may bind it to the underlying femoral condyle. This condition should be identified, as soft-tissue release will be less successful if the patella is not freed during operation.

In early mild cases, physiotherapy - that is, active exercises, passive manipulations, serial casts and reversed dynamic traction (Stein and Dickson 1975) - may prevent and correct flexion deformity of the knee. Examination and gentle manipulation under anaesthesia combined with local steroid injection are occasionally helpful when the deformity is principally due to muscle spasm (Allen et al. 1986), although great caution is needed because of the osteoporosis often seen in many of these patients.

In cases of more severely fixed deformity, surgical correction by soft-tissue release may be indicated. Preoperative investigations include radiography, arthrography and gentle examination under anaesthesia. Arthroscopy has not always been of great benefit as the capsular contracture prevents proper distension of the joint, making adequate access impossible.

Soft-tissue release procedures have been the mainstay of the treatment of paralytic, spastic and congenital 


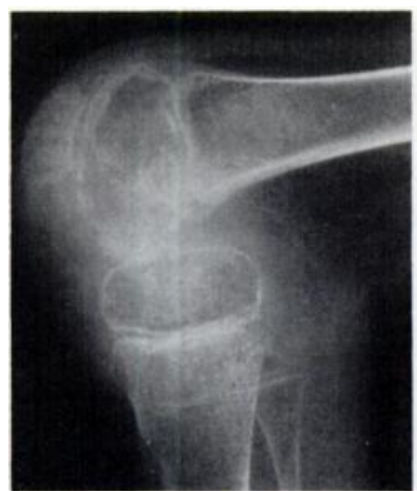

Fig. 2

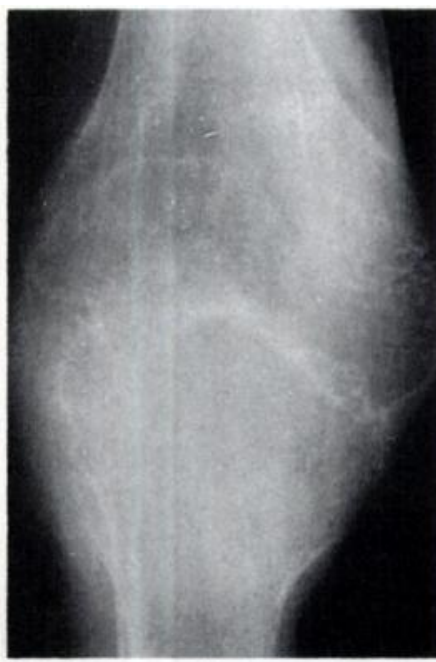

Fig. 4

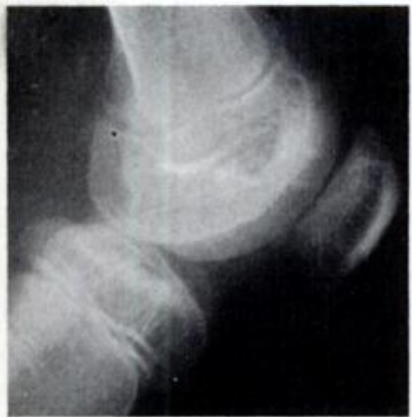

Fig. 8

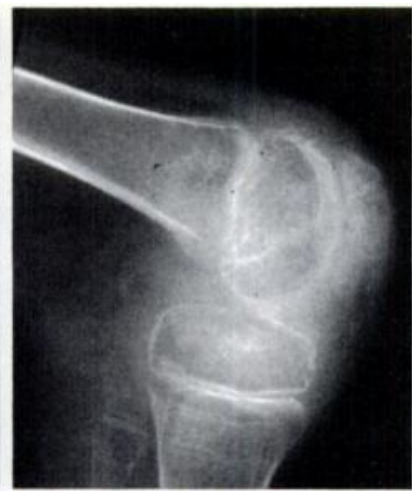

Fig. 3

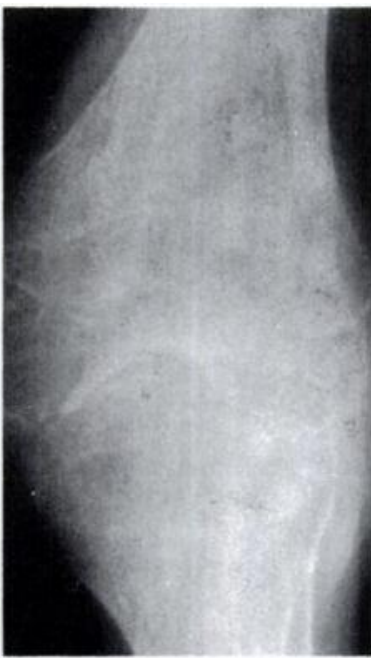

Fig. 5

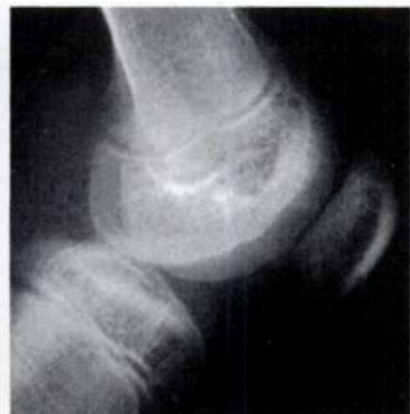

Fig. 9

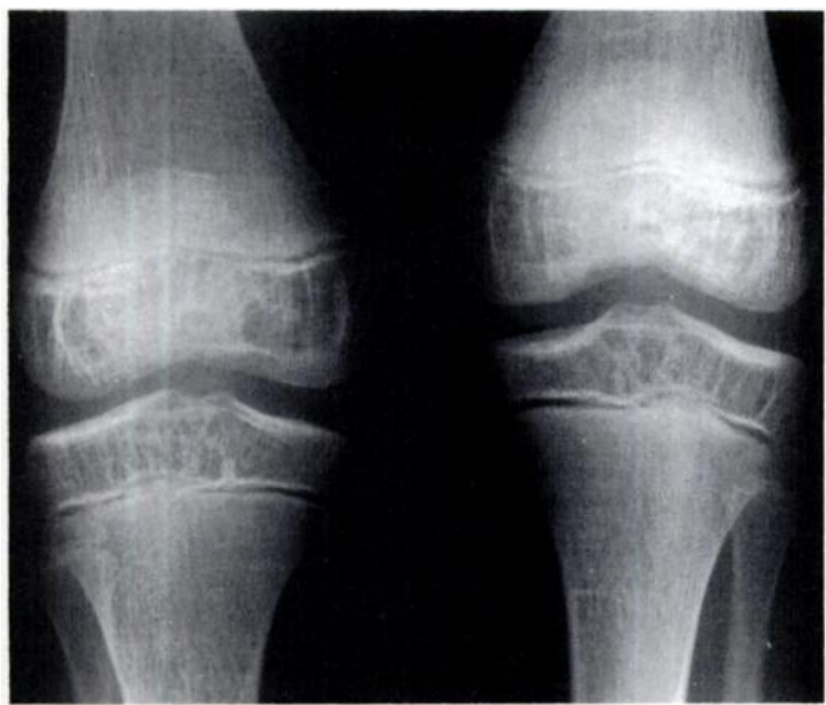

Fig. 10

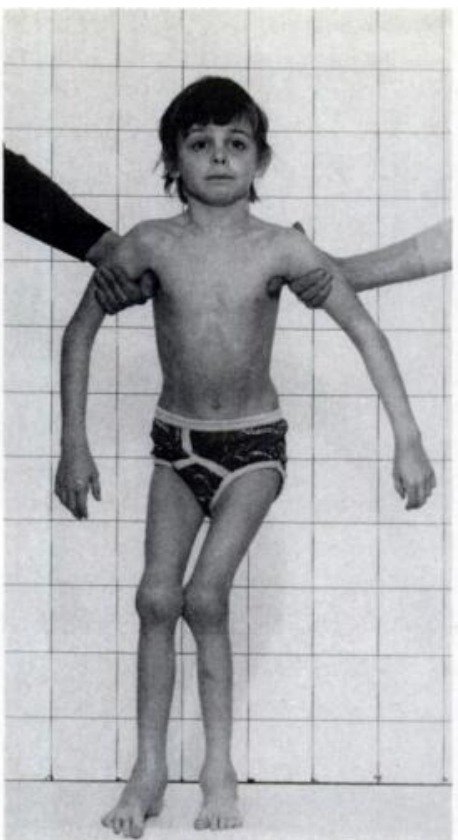

Fig. 6

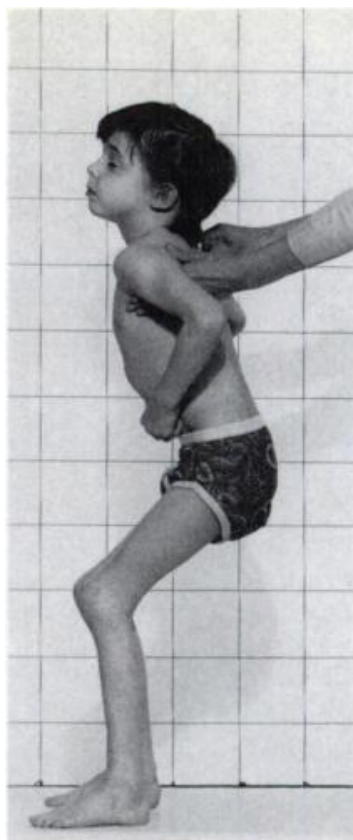

Fig. 7

Figures 2 to 5 - Radiographs of a six-year-old boy who had developed pauci-articular juvenile chronic arthritis at the age of 4 years 10 months: there is evidence of osteoporosis, early femoral epiphyseal overgrowth and tibial subluxation. Figures 6 and $7-$ Clinical photographs of patient; two years after onset of his disease, he was totally dependent upon his parents, wheelchair-bound and suffering considerable pain. Figures 8 to 10 - Four years later radiographs reveal an almost normal appearance; bilateral soft-tissue release procedures had been performed four months after the radiographs shown in Figures 2 to 5 . Figures 11 and 12 - Three years later, after a full regim $: n$ of medical and rehabilitation treatment and the bilateral release procedures, he is independent and painfree; he now runs middledistance races for his school.

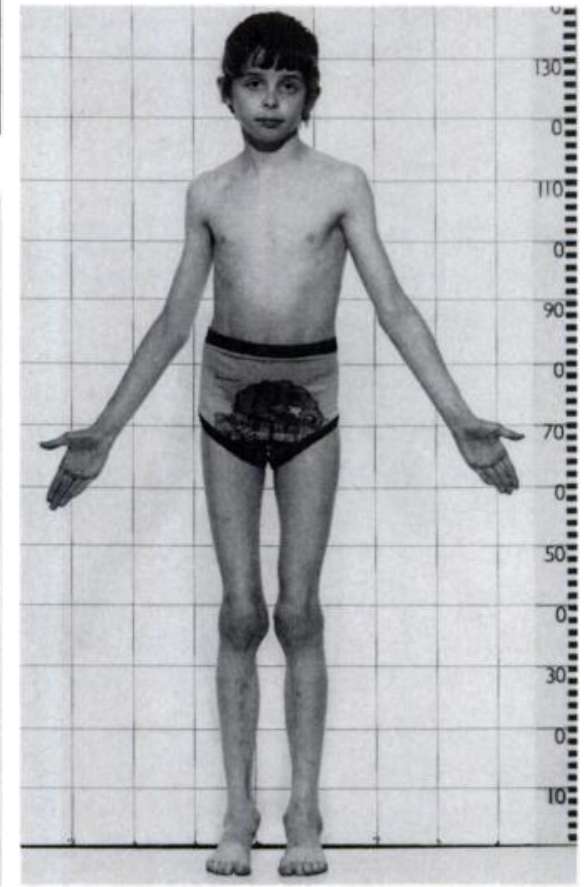

Fig. 11

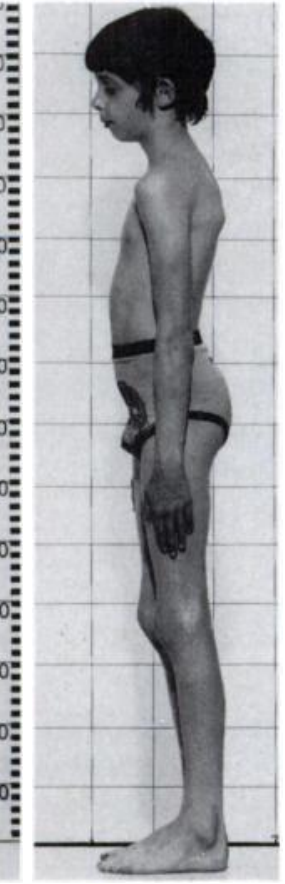

Fig. 12 
joint deformities. Jakubowski and Ruszczynska (1967) have proposed these techniques to treat juvenile chronic arthritis, as have Granberry and Brewer (1974). It has also been suggested (Ansell and Swann 1983) that, by decompressing the involved joint and improving the range of movement, the procedure may improve nutrition of the articular cartilage and thus facilitate healing by fibrocartilage (Figs 2 to 10 ).

Radiographic evidence of residual tibial subluxation was present in five cases, but this was not associated with a less satisfactory clinical result. The release was associated with encouraging diminution in pain but, in a disease with a tendency to remit, this result must be viewed with caution. Patient satisfaction and improved capabilities were generally gratifying, as in the case of a young boy, who, after soft-tissue release, is now able to run middle distance races for his school (Figs 11 and 12).

Rydholm, Brattström and Lidgren (1986) concluded also that soft-tissue release of the knee in juvenile chronic arthritis was worthwhile, but made no comment about its effect on pain or on the functional capabilities of the patient. We feel that posterior soft-tissue release of the knee can produce an acceptable correction of flexion contracture and decompress the joint, thereby reducing pain and encouraging healing of the articular surface.

It is important that the child's disease is well controlled by a paediatric rheumatologist and that extensive physiotherapy is available before and after operation. Finally, the child and his parents must fully understand and co-operate in the medical, surgical and physiotherapy regimes if a satisfactory result is to be obtained.

\section{REFERENCES}

Aichroth P, Freeman MAR, Smillie JS, Souter WA. A knee function assessment chart. J Bone Joint Surg [Br] 1978;60-B:308-9.

Allen RC, Gross KR, Laxer RM, Malleson PN, Beauchamp RD, Petty RE. Intra-articular triamcinolone hexacetonide in the management of chronic arthritis in children. Arthritis Rheum 1986;29:997-1001.

Ansell BM, Swann M. Review article: the management of chronic arthritis of children. J Bone Joint Surg [Br] 1983;65-B:536-43.

Arden GP, Ansell BM. Surgical management of juvenile chronic polyarthritis. London etc: Academic Press, 1978.

Fiszman P, Ansell BM, Renton P. Radiological assessment of knees in juvenile chronic arthritis (juvenile rheumatoid arthritis). Scand J Rheumatol $1981 ; 10: 145-52$.

Granberry WM, Brewer EJ. Early surgery in juvenile rheumatoid l
Jakubowski S, Ruszczynska J. The possibility of surgical treatment in cases of juvenile rheumatoid arthritis. Acta Rheumatol Scand 1967;13:113-8.

Rydholm U, Brattström H, Lidgren L. Soft tissue release for knee flexion contracture in juvenile chronic arthritis. $J$ Pediatr Orthop $1986 ; 6: 448-51$.

Salvati EA, Wilson PD Jr. Long-term results of femoral-head replacement. J Bone Joint Surg [Am] 1973;55-A :516-24.

Somerville EW. Flexion contractures of the knee. J Bone Joint Surg [Br] 1960;42-B:730-5.

Stein H, Dickson RA. Brief notes: reversed dynamic slings for knee flexion contractures in the hemophiliac. J Bone Joint Surg [Am] 1975;57-A :282-3.

Swann M, Ansell BM. Soft-tissue release of the hips in children with juvenile chronic arthritis. J Bone Joint Surg [Br] 1986;68-B:404-8. 